\title{
A Utilização de Softwares no Ensino de Funções Quadráticas
}

\author{
Using Softwares to Teach Quadratic Functions
}

\author{
Lúcia Andréia de Souza Rocha ${ }^{1}$, Cristiana Andrade Poffal ${ }^{2}$ e \\ Cinthya Maria Schneider Meneghetti ${ }^{3}$
}

1,2,3,4 Universidade Federal do Rio Grande, RS, Brasil

\begin{abstract}
Resumo
Este artigo tem como objetivo apresentar uma maneira diferente de abordar os conceitos de funções quadráticas, propondo exercícios de motivação e de fixação de conteúdos, com questões contextualizadas e voltadas para o dia-adia do educando. Pretende-se auxiliar os docentes e tornar, assim, a aprendizagem mais prazerosa, desmistificando a Matemática e oportunizando aos alunos a aplicação dos conceitos matemáticos em seu cotidiano. Utilizando as ferramentas tecnológicas já disponíveis na maioria das escolas de Educação Básica, apresentar-se-ão atividades usando pelo menos um software livre para inspirar os professores na elaboração de suas aulas e, consequentemente, ajudar os discentes na construção do seu conhecimento.
\end{abstract}

Palavras-chave: Função Quadrática. Exercícios de contextualização de funções. Tecnologia

\begin{abstract}
This article aims to present a different way of teaching quadratic functions concepts. It proposes warm-up and review exercises related to the students' daily lives. It intends to help teachers during class preparation, as a consequence making learning more pleasurable for the students, demystifying mathematics, providing opportunities of application of several mathematical concepts on the students lives. Using technological tools already available in most Basic Schools, we will present activities using at least one free software to inspire teachers while preparing their lessons and consequently help students build their knowledge.
\end{abstract}

Keywords: Quadratic function. Contextualizing Function Exercises. Technology 


\section{Introdução}

Nas últimas décadas, o ensino da Matemática no Brasil vem apresentando progressos importantes com propostas de novas metodologias como a utilização de jogos educativos, materiais concretos, pesquisas que visam relacionar a matemática com o cotidiano dos alunos, além de softwares especialmente desenvolvidos para este fim. Porém, em muitos locais, ainda é ensinada de forma tradicional, sem muitos atrativos para o aluno e por esse motivo, a matemática acaba, para um grande número de alunos, se tornando difícil.

Percebe-se que a informática está cada vez mais presente nas escolas. Até mesmo as escolas públicas possuem computadores que podem ser utilizados tanto por professores quanto por alunos. Muitos desses equipamentos foram adquiridos através do Programa Nacional de Tecnologia Educacional (PROINFO), programa do governo federal que visa à informatização das escolas públicas, tanto municipais quanto estaduais, com a criação de laboratórios de informática. De acordo com Secretaria de Educação Básica (SEB), a escolha das escolas que receberão os laboratórios se dará da seguinte forma: no âmbito estadual, a escolha é feita pelas coordenadorias, e no âmbito municipal, pelos prefeitos.

Apesar de grande parte das escolas já possuírem computadores, na maioria das vezes tais equipamentos não são utilizados pelos professores de Matemática. Geralmente são usados como ferramenta de pesquisa por professores de História, Educação Artística ou Geografia.

Segundo Almeida (1998), a resistência ao uso do computador na escola não ocorre por má vontade dos professores ou por dificuldades de utilizá-lo, mas sim pela estrutura curricular escolar, que acaba com qualquer projeto que não se adapte ao esquema de grades com aulas de cinquenta minutos. No entanto, ao conversar com alguns professores, principalmente os de Matemática, constata-se sua resistência em utilizar tal ferramenta. Às vezes por falta de tempo de preparar as atividades. Outras, por acomodação, pois levar as turmas para o laboratório de informática demanda tempo e preparação, tirando o professor de sua zona de conforto, além da falta de preparo para utilizar tecnologias.

Faz pouco tempo que os cursos de licenciatura inseriram disciplinas voltadas à utilização de tecnologias na educação. Na Universidade Federal do Rio Grande do $\mathrm{Sul}^{1}$, são ministradas disciplinas como Computador na Matemática Elementar I, que visa o desenvolvimento de conceitos e aplicações dentro do ambiente virtual LOGO, e Educação Matemática e Tecnologia disciplina que analisa a utilização de softwares diversos no ensino-aprendizagem

\footnotetext{
${ }^{1}$ Grade curricular disponível em http / /www.ufrgs.br/ufrgs/ensino/graduacao/cursos / exibeCurso?cod_curso $=335$ acessado em 5.07.2013.
}

de matemática, além de construção de referencial teórico na área de tecnologias aplicadas à Educação Matemática.

A Universidade Federal do Rio Grande ${ }^{2}$, oferece as disciplinas do curso de matemática Tecnologias Aplicadas à Educação I e II e a Universidade Federal de Pelotas ${ }^{3}$ ministra Tecnologias Avançadas no Ensino de Matemática e Programação em softwares de matemática, disciplinas de caráter obrigatório que visam desenvolver habilidades no uso de tecnologias, assim como a análise de diferentes softwares destinados ao ensino de conteúdos matemáticos.

Atualmente, tanto os currículos quanto os professores devem se adaptar a essa realidade. É passado o tempo em que, para alcançar seus objetivos, bastava que o educador preparasse seu aluno para um vestibular, ou algo parecido. De acordo com Sancho (1998), ao interagir com novas tecnologias o ser humano transforma profundamente a si e ao meio no qual vive, daí a importância de inseri-las na educação.

A fim de que os professores de matemática possam utilizar os computadores em suas aulas já existem vários softwares livres, ou seja, aquele tipo de programa que não necessita do pagamento de licença tais como o Régua e Compasso, Wingeom, Geogebra, Octave, Winplot e Logo, por exemplo. Com eles é possível trabalhar e ilustrar quase todo o conteúdo do Ensino Fundamental e Médio. Por exemplo, softwares como Régua e Compasso, Cabri, Wingeom, e Geogebra auxiliam em conteúdos de Geometria Plana e Espacial, assim como na Trigonometria. Enquanto, com o Octave, é possível trabalhar álgebra, matrizes e determinantes, com o Winplot ou Geogebra, pode ser abordado o conteúdo de funções, dentre tantos outros conteúdos que os alunos têm dificuldades de compreensão.

O estudo de funções constitui dos temas mais importantes do programa de Matemática do Ensino Básico. Sua abordagem pode iniciar no Ensino Fundamental e se estender até a Educação Superior. O objetivo deste trabalho não é revisar conceitos, mas sim contribuir para facilitar a aprendizagem dos discentes propondo atividades para serem resolvidas com o auxílio de softwares matemáticos e situações contextualizadas para ilustrar os conceitos de funções quadráticas. Fonseca (2011) fez um trabalho interessante sobre funções afins contextualizadas e seu trabalho motivou o estudo de funções quadráticas através de situações contextualizadas e exercícios de motivação e fixação. Pretende-se, com este estudo, auxiliar os professores dinamizando suas aulas e tornando o conteúdo mais significativo para os educandos.

\footnotetext{
${ }^{2}$ Grade curricular disponível em http //www.furg.br/bin/cursos/tela_qsl_visual.php?cd_curso $=102$ acesso em 5.07.2013

${ }^{3}$ Lista de disciplinas disponíveis em http / / ifm.ufpel.edu.br/dme/?page_id $=110$, acesso em 5.07.2013
} 
Este trabalho está dividido em cinco seções. $\mathrm{Na}$ seção 2, discute-se o estudo de funções e sua abordagem nos livros didáticos. Na terceira seção, comenta-se a utilização de tecnologias no estudo de funções e na seção 4, disponibilizam-se atividades resolvidas, divididas por temas específicos para que o professor possa escolher qual assunto e o tipo de exercício. As atividades foram resolvidas detalhadamente, com ilustrações das telas dos programas, utilizando os softwares Winplot ou wxMaxima, porém o professor pode optar por resolvê-las com outros softwares de sua preferência.

\section{O estudo de funções}

O aprendizado faz parte da natureza humana e o indivíduo aprende a todo o momento, em situações cotidianas, na relação com outras pessoas, e com o passar do tempo, tudo flui naturalmente e a aprendizagem se torna significativa. O problema da aprendizagem escolar é que muitas vezes "a escola pode levar o aluno a situações nas quais o mesmo tem que decorar os estudos para passar nas provas" Shitsuka et al. (2012).

O excesso de cálculos, a predominância de processos algorítmicos e a quantidade de regras, na maioria das vezes desvinculadas das situações reais, tornam o aprendizado da matemática deficiente, monótono e desinteressante para grande parte dos alunos, inibindo suas fantasias e espontaneidade. Se, ao invés de proporem questões do tipo "arme e efetue", "calcule", "resolva as expressões", os professores apresentassem aos seus alunos problemas contextualizados com situações que se aproximassem da vida cotidiana, os estudantes teriam mais interesse e procurariam solucionar os problemas com criatividade e perspicácia, utilizando sua base de conhecimento adquirida ao longo do tempo, aprimorando sua capacidade de compreensão e interpretação, uma vez que o cotidiano é riquíssimo, está repleto de situações matemáticas.

Conforme os exemplos citados por Toledo (1997):

Sempre que precisamos tomar uma decisão importante, pesamos todos os fatores envolvidos e procuramos um meio de organizá-los da melhor forma, estudando as várias possibilidades; nesse momento, estamos utilizando o raciocínio combinatório. As pessoas que cozinham utilizam seus próprios algoritmos, e para aumentar ou diminuir o tamanho da receita empregam o raciocínio proporcional ("se para 4 xícaras de farinha coloco 3 ovos para 6 xícaras devo colocar..."); o mesmo faz um viajante ao calcular que velocidade média deverá imprimir ao carro para chegar ao seu destino em um determinado tempo.
Tendo em vista o exposto, deve-se melhorar a abordagem dada à matemática, visando uma educação de qualidade e mais significativa, pois a falta de sentido nos conteúdos acaba tornando-os mais difíceis do que realmente são.

O conteúdo de funções é um dos mais estudados na Educação Básica, começando no Ensino Fundamental com uma breve introdução, sendo aprofundado no Ensino Médio e até mesmo no Superior, em alguns casos. Apesar disso, ainda gera grandes dificuldades, muitas delas em virtude da forma como é abordado. Acreditase que teoria e o quadro não estejam sendo suficientes para tornar o assunto claro para os alunos.

Segundo Ávila (2003), quando se fala em função, é de grande importância definir o seu domínio, pois geralmente se fornece a lei e o domínio fica implícito como sendo o maior conjunto possível. Essa situação não é verdadeira, pois, às vezes, pode-se querer analisar o comportamento de uma função num certo intervalo do seu domínio, restringindo-o a um subconjunto.

Em geral, os alunos são apresentados à álgebra no sétimo ano, começando por equações do primeiro grau e sistemas. O conteúdo de funções deveria ser iniciado nas séries finais do Ensino Fundamental, em específico no último ano, segundo os PCN's Brasil (2000b) de matemática para o $3^{\circ}$ e $4^{\mathrm{o}}$ ciclos ${ }^{4}$. Porém, na maior parte das escolas, os alunos só se deparam com funções no Ensino Médio.

Ainda no sétimo ano, começa-se o estudo de pares ordenados, plano cartesiano, equações com duas incógnitas. Essa descontinuidade ou fragmentação dos conteúdos pode prejudicar em muito a aprendizagem dos alunos, já que quando chegam ao último ano não conseguem relacionar tais conteúdos. Se houvesse continuidade no nono ano, talvez os educandos conseguissem relacionar os conhecimentos já adquiridos facilitando a sequência de ensino pretendida pelo professor. Por exemplo, considerando que para as equações do primeiro grau com duas incógnitas, os alunos sabem que existem infinitas soluções, pois para cada valor dado a $x$ tem-se um valor distinto para $y$, e, não há, neste momento, representação gráfica que relacione ao estudo de funções. Veja o que consta em Ávila (2004) MEC/SEB ${ }^{5}$ Arquivos:

... o estudo de funções, na sua fase mais elementar, poderia iniciar-se, com grande vantagem, na sexta série, logo após o (ou simultaneamente ao) estudo das equações. De fato, ao estudar equa-

\footnotetext{
${ }^{4}$ Ciclos são períodos de dois ou três anos nos quais o Ensino Básico é dividido. Por exemplo, o $3^{\circ}$ ciclo corresponde aos $6^{\circ}$ e $7^{\circ}$ anos e o $4^{\circ}$ ciclo $8^{\circ}$ e $9^{\circ}$ anos.

${ }^{5}$ Funções e Gráficos num problema de frenagem - adaptado do artigo de Geraldo Ávila - coleção Explorando o ensino - matemática vol. 3 - disponível site do MEC em 02/2013
} 
ções a duas incógnitas, é da maior conveniência ensinar sua representação gráfica... o aluno pode ser levado, por um processo gradual de aprendizado, a descobrir, por si próprio que toda equação do primeiro grau a duas incógnitas tem por representação gráfica uma linha reta. (MEC/SEB arquivos, p. 95)

Na maioria das vezes, quando se pensa em função, acredita-se que deve haver uma fórmula ou lei que relacione as grandezas envolvidas, mas deve ficar claro para os alunos que muitos exemplos práticos envolvendo funções não são definidos por fórmulas, dentre eles os exames cardíacos (onde tem-se a relação número de batimentos em função do tempo) ou os gráficos encontrados em jornais e revistas que estão relacionados a assuntos diversos, como o crescimento de uma empresa durante um determinado período de tempo.

Para iniciar este trabalho pesquisou-se em livros didáticos de Ensino Fundamental e Médio suas abordagens dos conceitos relacionados a funções: motivação ao estudo, definições, aplicações, gráficos, exercícios e utilização de recursos computacionais.

Segundo Brasil (2000a), ${ }^{6}$ ao estudo de funções deve ser dada menor ênfase à linguagem formal que cerca esse tema, assim como ao estudo de funções injetoras, sobrejetoras, compostas e modulares. Também por Brasil (2000a), os problemas de aplicação e contexto devem ser o motivo para o estudo de funções e não podem ser deixados para o final, devido à riqueza de situações que envolvem funções. $\mathrm{O}$ ensino não deve se privar de mostrar que o conteúdo estudado permite analisar de forma crítica e analítica as situações cotidianas. Porém durante o Ensino Médio, o estudo de funções não vem cumprindo esses requisitos: são fórmulas, leis, definições e teoremas que ao final significam pouco na vida dos estudantes, contribuindo para que eles concluam o curso sem cumprir objetivos do ensino de matemática.

Acredita-se que com a utilização de softwares nas aulas de matemática, mesmo os alunos com dificuldades em questões de aritmética, por exemplo, se mostrariam interessados e teriam maior incentivo para participar da solução dos problemas propostos pelo professor. Este deixa de ser um mero expositor que transmite instruções passo a passo, e se torna um incentivador e orientador das ideias geradas pelos alunos. Assim, os discentes participam ativamente da aula "fazendo matemática", isto é, construindo seu próprio conhecimento matemático e não ficam mais passivamente, apenas observando a "matemática ser feita pelo professor".

Na próxima seção, discute-se o uso de tecnologias no ensino de funções.

\footnotetext{
${ }^{6}$ Está sendo feita uma distinção entre $\mathrm{PCN}$ e $\mathrm{PCN}^{+}$, pois há os dois tipos de PCN's disponíveis no site do Ministério da Educação
}

\section{As Tecnologias e o Ensino de Fun- ções}

A matemática é uma ciência exata e por necessitar de tantos cálculos acaba se tornando difícil aos olhos dos alunos, que se preocupam em decorar fórmulas, pensando que assim terão maior facilidade na hora de testar seus conhecimentos em uma prova. É uma disciplina de popularidade negativa e por não parecer muito aprazível, é responsável por altos índices de reprovação e de evasão escolar. De acordo com Gonzatto (2012), a combinação de aulas pouco atrativas com o desinteresse dos alunos e a formação deficiente dos professores, também contribuem para os resultados ruins do ensino da matemática no país.

Atualmente existem muitos recursos, tecnológicos ou não, que têm como objetivo facilitar a aprendizagem e, consequentemente, a aquisição (ou construção) do conhecimento. Na matemática, embora não sejam muito usados, não é diferente. Segundo Ambrósio (1986), o professor pode utilizar o computador como um quadro negro e mesmo assim o uso dele permite um grau maior de interação com a aula, pois apenas o uso da máquina, por si só, já envolve os alunos, deixando-os mais entusiasmados pela resolução dos problemas propostos, que pode ser feita individual, em grupos ou coletivamente. Porém, essa atitude não é a mais adequada, pois já existem inúmeros softwares matemáticos para auxiliarem aprendizagem dos alunos e que podem ser empregados nos mais variados ramos da Matemática.

Acredita-se que a maior parte dos problemas dessa disciplina esteja na forma como ela é abordada. São cálculos, desenhos e gráficos soltos em folhas de exercícios nos cadernos dos estudantes, sem nenhuma significação real para eles. Veja o que diz Neves (2008) sobre matemática e sua relação com as tecnologias.

A matemática sempre teve uma relação muito especial com as tecnologias, desde as calculadoras, o computador, os sistemas multimídia e a internet.

O uso de tecnologias no ensino de matemática proporciona novas formas de ensinar e de aprender. Essas novas formas vêm provocando uma revolução nas práticas tradicionais de ensino que avançam em direção a uma prática pedagógica interdisciplinar voltada para a aprendizagem do aluno-sujeito. Também estabelecem uma nova relação professor-aluno marcada por uma maior interação e cooperação. Observe o que diz Valente (1998), com relação ao uso do computador em sala de aula.

O computador pode ser um excelente recurso para promover a passagem da informação para o usuá- 
rio ou promover a aprendizagem. No entanto, da análise dos software é possível entender que o aprender não deve estar restrito ao software mas à interação professor- aluno-software.

Assim como a maior parte dos conteúdos de Matemática, o estudo de funções também costuma ser desenvolvido de forma tradicional, geralmente com o auxílio de um livro didático, apesar de, atualmente, se encontrar vários trabalhos que envolvam a utilização de tecnologias para esse estudo: são monografias, dissertações, artigos e até mesmo apostilas que mostram como utilizar determinados softwares matemáticos no ensino desse conteúdo.

Maia $(2007)^{7}$ avalia livros didáticos de Ensino Fundamental e Médio para verificar como é desenvolvido o conteúdo de funções quadráticas. Posteriormente apresenta um tutorial, ensinando como utilizar o Winplot, para a seguir serem resolvidos exercícios de funções quadráticas no software. Os exercícios resolvidos visam analisar o comportamento gráfico das funções quadráticas do tipo $f(x)=a x^{2}+b$ quando altera-se o valor de $a$, além de translações. Essas questões levam o aluno a analisar visualmente o que ocorre com o gráfico da função inicial $f(x)=x^{2}$ ao somar ou diminuir constantes, assim como o que ocorre com a parábola quando se altera o valor de $a$ fazendo $0<a<1, a>1$ e $a<0$.

Fonseca (2011) ${ }^{8}$ faz um estudo de funções lineares através do Nippe Descartes, programa desenvolvido por um órgão vinculado ao Ministério da Educação da Espanha. Tal aplicativo possibilita que sejam criadas atividades interativas através da internet para as aulas dos professores. Nessa obra são trabalhadas áreas de figuras planas, variação dessas áreas através de funções lineares, cálculos de proporcionalidade e distância em função do tempo.

Grande parte dos professores, que atuam no Ensino Médio, faz a construção gráfica de funções a partir de tabelas onde são atribuídos valores de $x$ e calculados os valores de $y$. Tendo em vista o exposto, pode-se ter como aliado para a construção gráfica as planilhas de cálculo como o Excel e Br Office, por exemplo, programas conhecidos, muitas vezes utilizados para fechamento de notas, mas pouco utilizado nas aulas. Este tipo de programa vem sendo utilizado em diversos ramos da matemática. Conceição (2013) utilizou planilhas da cálculo para fazer o estudo de transformações lineares no plano, ele explica passo a passo como são feitas as transformações, inclusive ilustra tais transformações com gráficos esboçados na própria planilha. São feitas também, detalhadamente, reflexões em torno dos eixos, origem e retas.

\footnotetext{
${ }^{7}$ Diana Maia - Dissertação de Mestrado em Educação Matemática pela PUC/SP, 2007

${ }^{8}$ Vilmar Gomes da Fonseca, dissertação do programa de Pósgraduação em Ensino de Matemática da Universidade Federal do Rio de Janeiro - UFRJ, 2011
}

Alexandre (2012), estuda diversos tipos de funções utilizando o software excel. No estudo de funções quadráticas ele faz a construção gráfica com base numa tabela de valores, na qual são atribuídos valores para $x$ e calculados os valores de $y$. Neste gráfico, é possível analisar as raízes da função assim como a concavidade da parábola. Todo o trabalho é descrito passo a passo, facilitando, assim, o entendimento.

Santos (2013) desenvolveu um aplicativo para o estudo de funções quadráticas, tal software é executado na plataforma Barland Delphi 7 e calcula as raízes de funções polinomiais de segundo grau, pontos de máximo e mínimo e faz gráficos.

Ribeiro (2013) inicia seu trabalho estudando a história das funções, fazendo, posteriormente, uma abordagem formal sobre funções quadráticas, definição, zeros e forma canônica. Diferentemente de outros trabalhos, o autor relaciona funções quadráticas com progressões aritméticas e estuda funções sobre o contexto da Geometria Analítica. Neste trabalho são apresentadas atividades no Winplot e Geogebra, além de situações contextualizadas. Naquelas resolvidas com o Winplot, são feitas translações de gráficos de funções quadráticas e naquelas resolvidas com o Geogebra são feitos gráficos e marcados o vértice, os focos e a diretriz. São mostradas também animações dos parâmetros para estudar as variações gráficas de acordo com a variação dos coeficientes. $\mathrm{O}$ mesmo autor faz a construção de parábolas pela definição da Geometria Analítica.

Junior (2013) apresenta atividades de análise gráfica no software Geogebra, que exercitam translações verticais e horizontais, assim como variações na concavidade da parábola de acordo com o coeficiente $a$. Após cada atividade, há um questionário que deve ser respondido pelos alunos e uma avaliação do autor quanto ao número de acertos e erros cometidos por eles ao fazerem a interpretação gráfica.

Magarinus (2013) fez um trabalho baseado na utilização dos softwares Tracker e Geogebra, no qual foram apresentadas atividades que exploram o conceito de função e a relação entre as variáveis e situações de análise gráfica de funções afins e quadráticas. Todos os exercícios são devidamente ilustrados com telas do programa no qual foram resolvidas, facilitando a compreensão dos mesmos.

Para Gómez (apud Neves (2008)), o uso de tecnologias pode não ser a solução para os problemas que estão presentes no processo de ensino-aprendizagem de matemática, mas há grandes possibilidades de ele ser um agente catalizador no processo de mudança no ensino da matéria. Visando mudanças positivas no processo de ensino-aprendizagem de matemática é que se realiza esse trabalho, no qual utilizam-se softwares livres para fixar, revisar e motivar os alunos à estudarem funções quadráticas. 
Apesar de haver vários trabalhos nos quais são utilizados softwares no estudo de funções, a abordagem dada a esse estudo é diferente. Neste trabalho serão apresentadas resoluções de situações problemas envolvendo função quadrática com a utilização de software livre, além de atividades de fixação e motivação.

Na próxima seção, são apresentadas atividades propostas com os temas: esportes e análise gráfica. As atividades contêm sua solução passo a passo e dicas para auxiliar o trabalho do professor.

\section{Atividades Propostas}

Apresentam-se exercícios contextualizados e de análise gráfica, que visam a motivação dos alunos através de gráficos que, ao se interseccionarem, formam desenhos. Os exercícios podem ser aplicados para introduzir, revisar ou fixar os conceitos, ficando a cargo do professor decidir como prefere utilizá-los.

\subsection{Problemas matemáticos no âmbito espor- tivo: futebol e voleibol}

Nas questões a seguir, os alunos deverão determinar as leis das funções, assim como seus pontos de máximo e raízes. Serão revisados conceitos relativos a funções quadráticas.

\section{Atividade 1. Futebol}

Pré-requisitos: resolução de sistemas lineares (com três incógnitas) e funções quadráticas.

Material necessário: equipamento que tenha instalado o software Winplot ou similar, além do material escolar usual.

Tempo necessário: uma hora aula.

Exercício 1. Num jogo da Seleção Brasileira de Futebol, Neymar percebeu que o goleiro estava adiantado e resolveu jogar a bola por cobertura. Sabendo que o jogador encontrava-se a $40 m$ do gol, o goleiro estava a $13 m$ do gol e consegue alcançar 3,5m ao saltar, e a altura da bola em função da distância ao gol é mostrada na Tabela 1, responda:

Tabela 1: Altura em função da distância da bola ao gol

\begin{tabular}{cc}
\hline Distância da bola ao gol & Altura da Bola \\
$m$ & $m$ \\
\hline 40 & 0 \\
35 & 2 \\
30 & 3,5 \\
25 & 4,5 \\
\hline
\end{tabular}

a) É possível expressar a lei que relaciona a distância com altura da bola através de uma função quadrática?

b) Faça o gráfico da função que relaciona distância da bola ao gol com sua altura no winplot.

c) Qual é a altura máxima alcançada pela bola?

d) O goleiro consegue alcançar a bola ou a bola o encobre?

e) Considerando que a trave do gol tem 2,4m de altura e que o goleiro não pegue a bola. Ela vai entrar na goleira?

\section{Resolução:}

\section{Dicas para o professor}

Explique aos alunos como as equações devem ser digitadas, lembrando que não se deve colocar vírgula nos números decimais e sim um ponto;

As operações são realizadas com os mesmos símbolos das planilhas de cálculo, conforme destaca-se a seguir:

+ para soma e - para subtração;

/ para divisão e $*$ para multiplicação;

$\wedge$ para potenciação;

Para visualizar melhor os gráficos, pode-se afastar a imagem ou aproximála utilizando as teclas $\operatorname{PgU} \mathrm{p}$ e $\operatorname{PgDn}$, assim como usar as setas do teclado para enquadrar a imagem;

Se achar necessário, dramatize a situação descrita no problema.

a) É possível expressar a lei que relaciona a distância com altura da bola através de uma função quadrática?

Observe que ao lançar um objeto, neste caso uma bola, sua trajetória pode ser aproximada por uma parábola e nesse caso a altura da bola pode ser calculada como $f(x)=a x^{2}+b x+c$. Assim, para resolver esse item, o aluno deverá encontrar a solução do sistema de três equações e três incógnitas $(a, b, c)$, já que o software Winplot não resolve sistemas lineares.

Considere que a goleira está na origem dos eixos coordenados. Segundo a Tabela 1 quando a bola está a $40 \mathrm{~m}$ do gol está no chão (altura $0 \mathrm{~m}$ ), quando está a $35 m$, sua altura é de $2 m$ e quando está a $30 m$ sua altura é de $3,5 m$, ou seja, $f(40)=0, f(35)=$ 


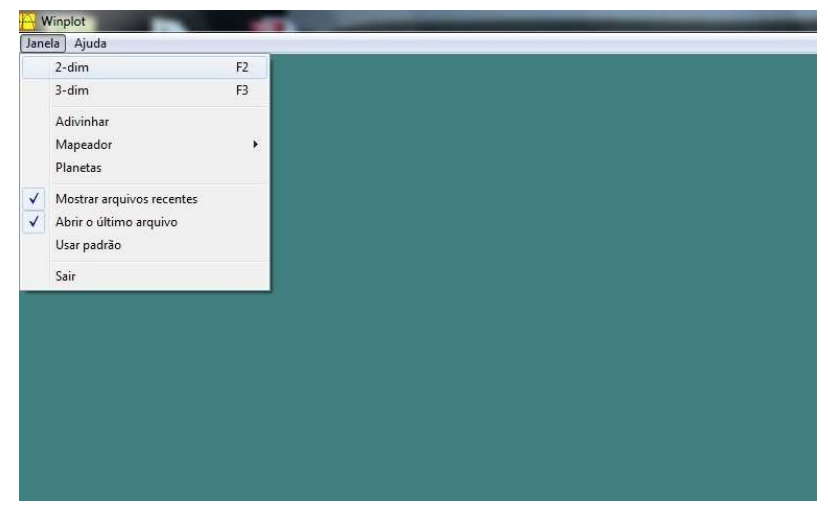

Figura 1: Seleção da janela em 2D

2 e $f(30)=3,5$. Com base nesses dados será formado o sistema de equações:

$$
\begin{aligned}
1.600 a+40 b+c & =0 \\
1.225 a+35 b+c & =2 \\
900 a+30 b+c & =3,5 .
\end{aligned}
$$

Para chegar ao sistema (1) basta fazer as substituições dos valores de $x$ e de $y$ na função $f(x)=$ $a x^{2}+b x+c$.

A solução do sistema (1) é $a=-\frac{1}{100}=-0,01$, $b=\frac{7}{20}=\frac{35}{100}=0,35$ e $c=2$. Logo, a função obtida como resposta para o item $a$ é:

$$
f(x)=-0,01 x^{2}+0,35 x+2 .
$$

b) Faça o gráfico da função que relaciona distância da bola ao gol com sua altura no winplot.

Na tela inicial winplot, escolhe-se a opção 2-dim, isto é, o gráfico será esboçado em duas dimensões. De acordo com a Figura 1.

Em seguida, escolhe-se Equação $\rightarrow$ 1. Explícita. Observe a Figura 2.

O comando anterior abre a janela da Figura 3, onde deve ser digitada a expressão da forma $a x^{2}+b x+c$ com os valores de $a, b$ e $c$ encontrados no item a. Lembre-se de que, caso seja escolhido trabalhar com números decimais, deve ser colocado um ponto no lugar da vírgula.

Para que o gráfico seja visualizado no intervalo adequado, clica-se em Travar Intervalo, fazendo $x$ variar de 0 a 40, conforme Figuras 3 e 4.

Ao pressionar Enter aparecerá a tela da Figura 5, com o gráfico desejado. Para se ter uma visualiza-

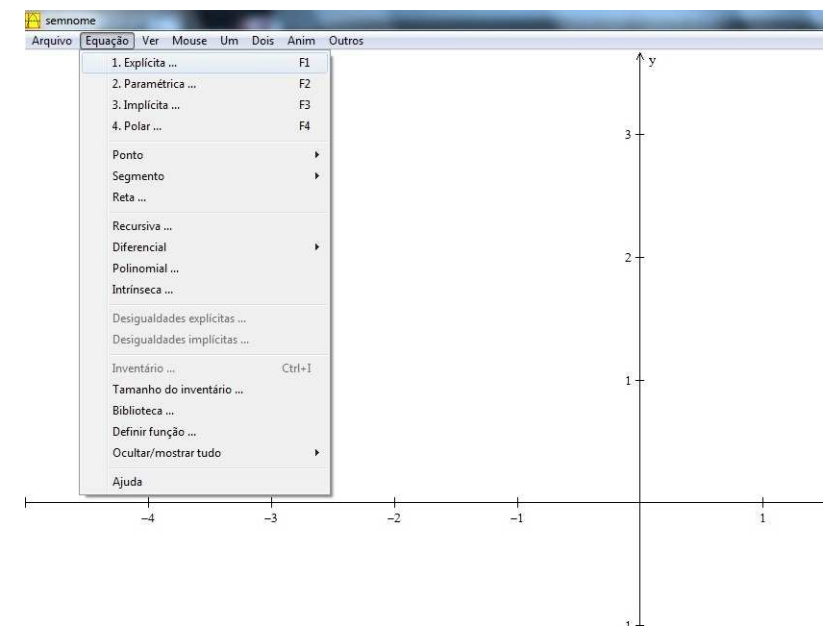

Figura 2: Selecionando Equação Explícita

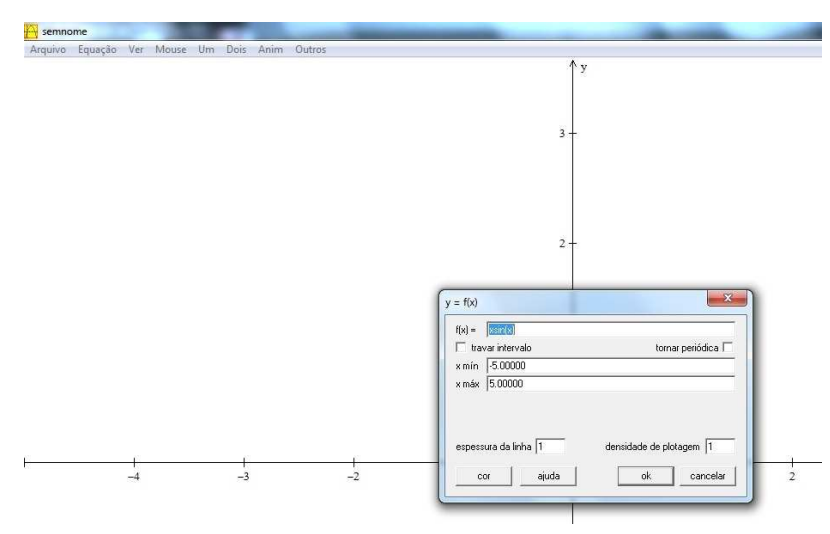

Figura 3: Janela para digitar Equação Explícita

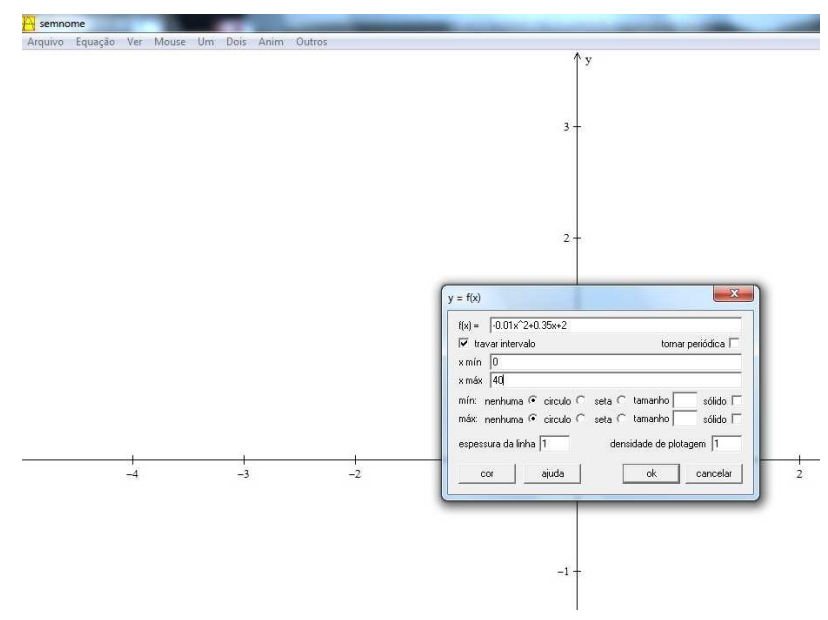

Figura 4: Equação digitada e intervalo fixado de acordo com o exercício 


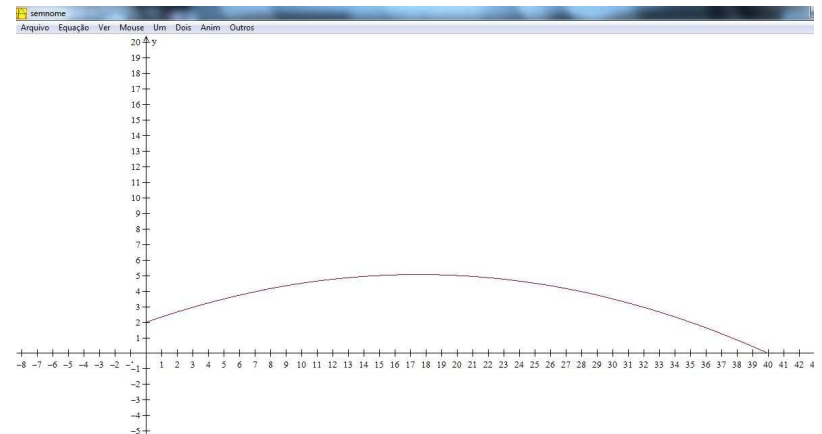

Figura 5: Gráfico da função

ção melhor do gráfico deve-se pressionar $\operatorname{Pg} D n$, assim como usar as setas do teclado.

c) Qual é a altura máxima alcançada pela bola?

Para determinar a altura máxima atingida pela bola, pode-se calcular as coordenadas do vértice da parábola através das fórmulas $x_{v}=-\frac{b}{2 a} \mathrm{e}$ $y_{v}=-\frac{\Delta}{4 a}$. Também pode-se calcular as raízes da equação e, utilizando-se da simetria da parábola, determinar a abscissa do vértice, através do ponto médio das abscissas das raízes para posteriormente calcular a ordenada. Em ambos casos, a resposta é $5,0625 \approx 5,06 \mathrm{~m}$.

d) O goleiro consegue alcançar a bola ou a bola o encobre?

Selecione a opção equação $\rightarrow$ ponto $\rightarrow(x, y)$. Conforme Figura 6. Em seguida digite o ponto com abscissa $x=13$ e ordenada $y=3,5$ que é a altura máxima alcançada pelo goleiro, de acordo com a Figura 7. Observe na Figura 8 que o ponto indica que a altura máxima do goleiro está abaixo da trajetória da bola e, por isso, ele não consegue alcançá-la quando está a $13 m$ do gol.

Você também pode fazer o gráfico da função $y=$ 3,5 , que é a altura máxima atingida pelo goleiro. Nos intervalos onde a trajetória da bola fica abaixo da reta, o goleiro tem possibilidade de defendê-la. Observe na Figura 9 que, para $x=13$, a trajetória da bola está acima da reta.

Pode-se perceber na Figura 8 que o ponto $(13,3,5)$ está abaixo da parábola, e na Figura 9, que a reta está abaixo da parábola quando $x=13$. Logo o goleiro não consegue alcançar a bola quando está a $13 m$ do gol, nem consegue defender o chute do atacante.

e) Considerando que a trave do gol tem 2,4m de altura e que o goleiro não pegue a bola. Ela vai entrar na goleira?

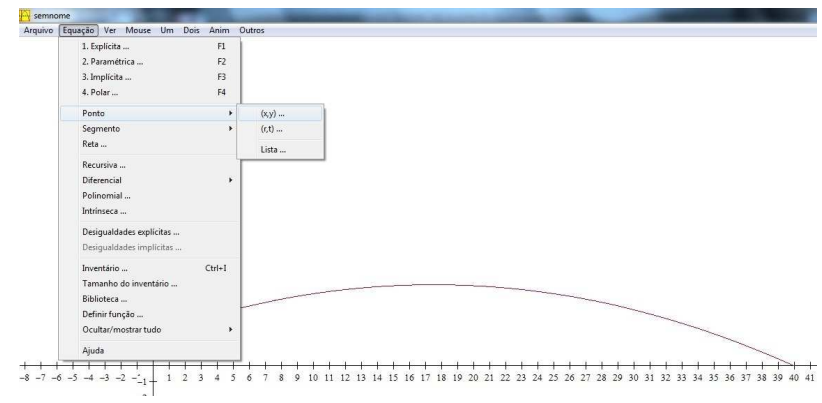

Figura 6: Janela que mostra quais comandos devem ser seguidos para marcar um ponto no plano

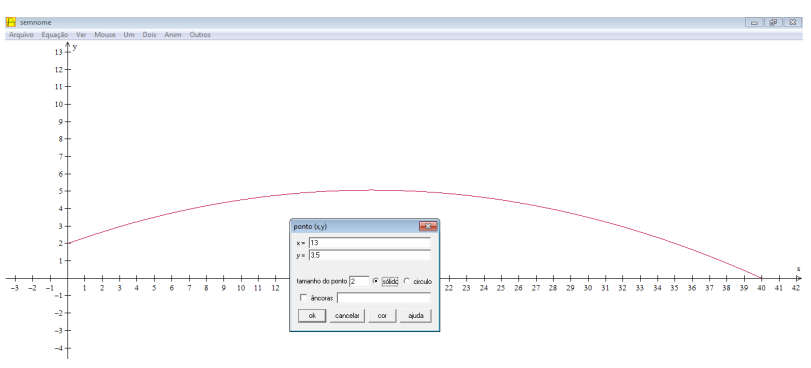

Figura 7: Digitação da Abscissa e Ordenada do ponto

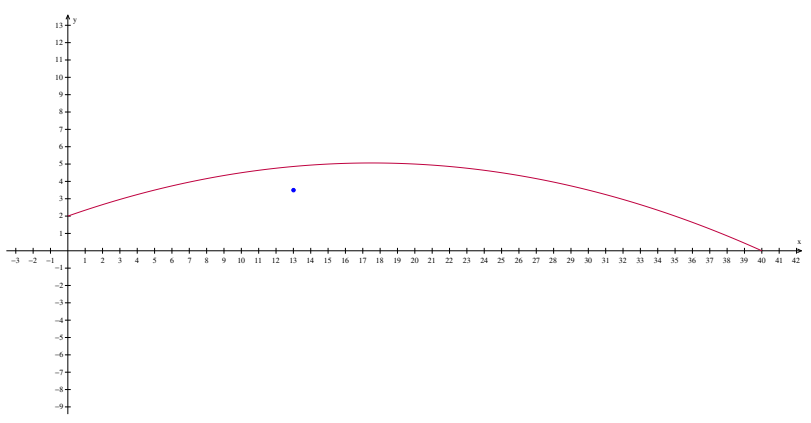

Figura 8: Ponto marcado abaixo da parábola

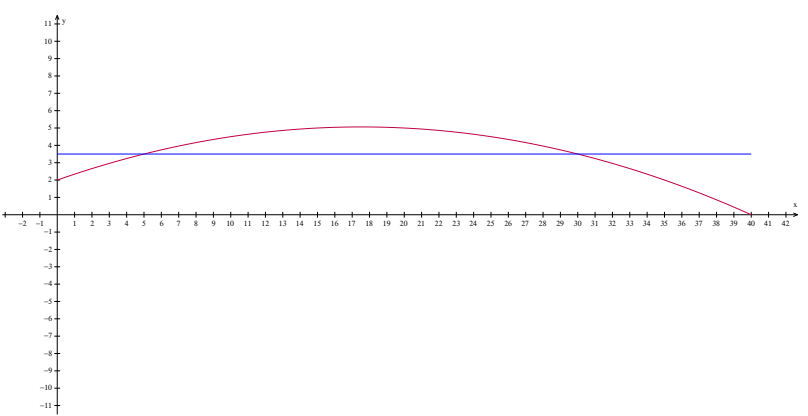

Figura 9: Gráfico da parábola e da reta $y=3,5$ na mesma janela 
Para resolução deste item é suficiente que o aluno observe o gráfico e perceba que $f(0)=2$ ou lembre que o valor de $c$, termo independente, indica onde o gráfico corta o eixo das ordenadas.

Conclui-se que a bola entrará no gol, pois $f(0)=2$ e a trave tem $2,4 m$ de altura.

Com a resolução do item $e$ termina-se o primeiro exercício. A seguir, destacam-se os pré-requisitos, material e tempo necessários para a resolução do próximo, que ainda trata do tema futebol.

Pré-requisitos: Funções quadráticas: raízes e pontos de máximo e mínimo.

Material Necessário: Software wxMaxima instalado.

Tempo necessário: Uma aula de 35 a $45 \mathrm{mi}-$ nutos ou uma hora/aula.

Exercício 2. Dois garotos estão jogando bola, um na frente do outro. Um deles chuta a bola segundo a trajetória dada pela função $f(x)=-0,25 x^{2}+1,75 x$, onde $x$ corresponde ao deslocamento horizontal e $f(x)$ é a altura da bola. Responda:

a) Se a bola cai no pé do segundo jogador, qual é a distância entre os jogadores?

b) Se bola bate na cabeça do segundo jogador quando este está a $6 m$ do primeiro, então qual é sua altura?

c) Obtenha o gráfico de $f(x)$ no software wxMaxima.

Resolução:

Dicas para o professor

Pergunte aos alunos como é possível aproximar a trajetória da bola;

Peça aos alunos que considerem um dos jogadores na origem dos eixos coordenados e comente que a altura máxima alcançada pela bola nada mais é do que o ponto máximo de uma função quadrática;

Também lembre-os de que a parábola é simétrica em relação ao seu eixo (reta que contém o vértice), ou seja, eles podem calcular as raízes da função e saberão que a abscissa do vértice está no ponto médio entre elas;

A forma de digitar as equações é a mesma do software Winplot.

a) Se a bola cai no pé do segundo jogador, qual é a distância entre os jogadores?

Considere que os pés dos jogadores estão sobre o eixo das abscissas. A bola, nesses pontos, tem

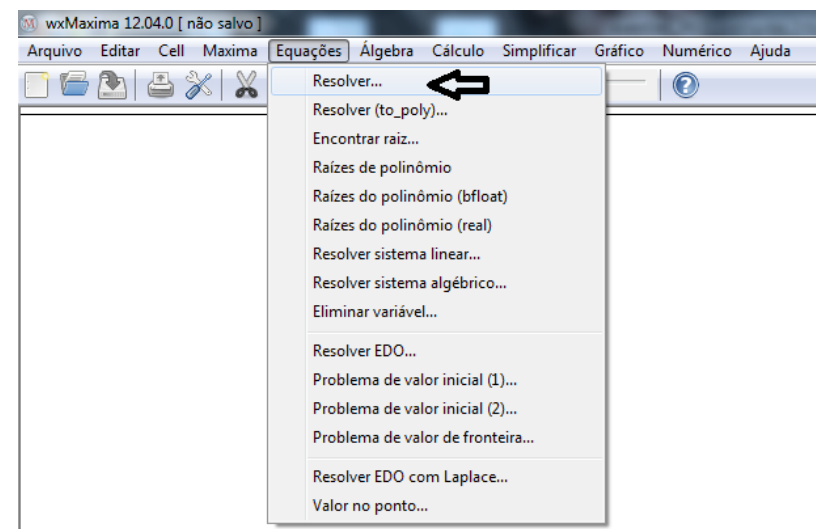

Figura 10: Janela do wxMaxima, menu Equações

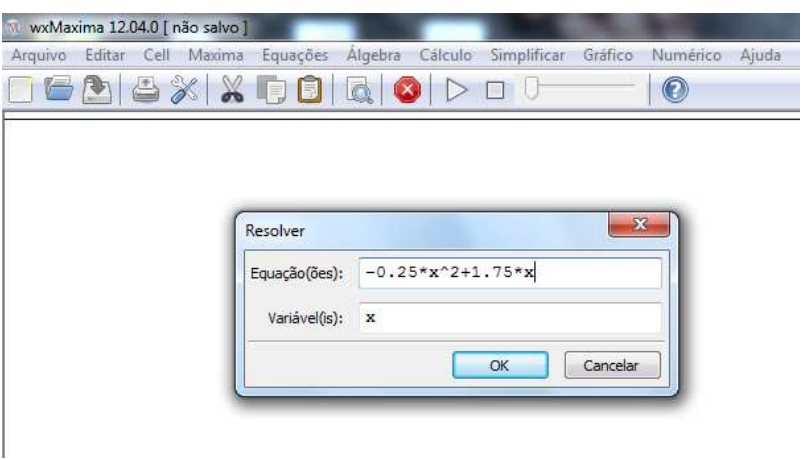

Figura 11: Janela para digitar a equação

altura zero e, por isso, devem ser calculadas as raízes da equação $-0,25 x^{2}+1,75 x=0$. Executase a seguinte sequência de comandos no software wxMaxima.

Após abrir o programa, clique em Equações $\rightarrow$ resolver, conforme Figura 10. Na Figura 11 é mostrado como a equação deve ser digitada.

A Figura 12 apresenta as raízes da equação.

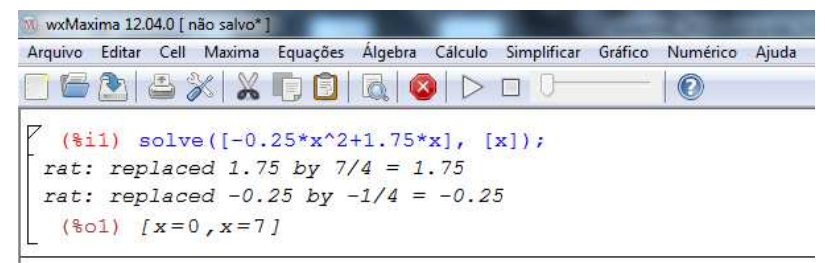

Figura 12: Raízes da equação 


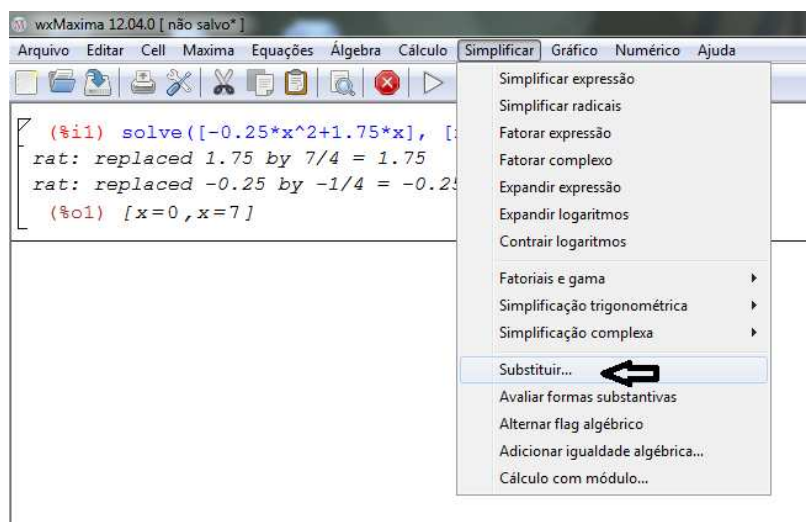

Figura 13: Menu Simplificar $\rightarrow$ Substituir

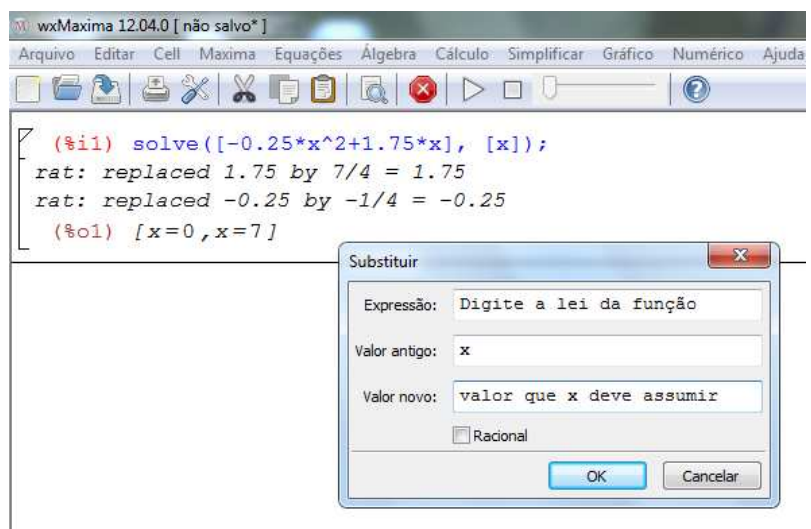

Figura 14: Digite a função para a qual se deseja calcular o valor no ponto

Logo, há uma raiz em $x=0$ e outra em $x=7$. Conclui-se que a distância entre os garotos é de $7 m$.

b) Se bola bate na cabeça do segundo jogador quando este está a $6 m$ do primeiro, então qual é sua altura?

Precisa-se determinar a imagem da função para $x=6$, isto é, $f(6)$. Siga os comandos das Figuras 13,14 e 15 .

Na Figura 16, obtém-se a resposta. O garoto tem $1,50 \mathrm{~m}$ de altura.

c) Obtenha o gráfico de $f(x)$ no software wxMaxima.

No wxMaxima é preciso clicar em Gráfico $\rightarrow 2 D$ e, posteriormente, digitar a equação restringindo o intervalo de variação de $x$. As Figuras 17 e 18 mostram como se deve proceder. Já na Figura 19 é mostrado o gráfico solicitado.

Também poderia ter sido solicitada a altura máxima atingida pela bola, para isso bastaria observar o gráfico e concluir que a altura máxima ocorre

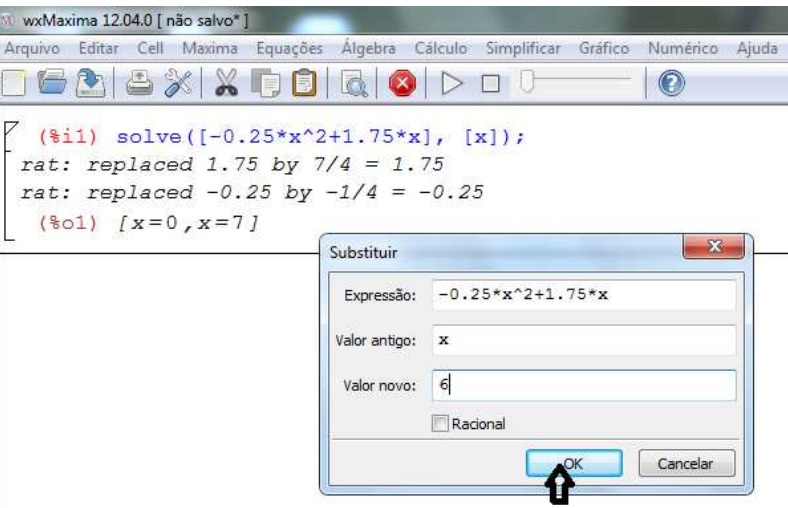

Figura 15: Função digitada

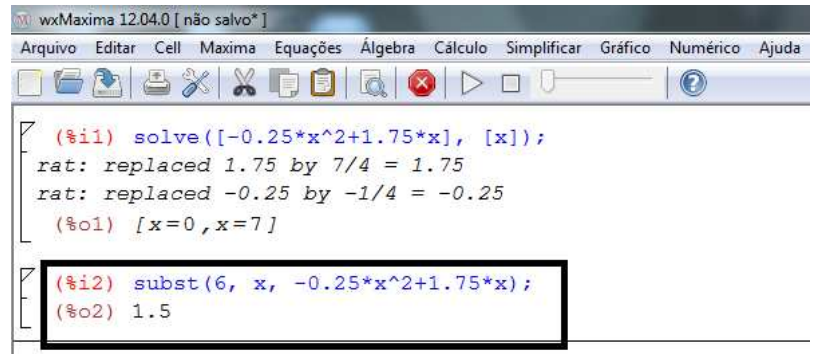

Figura 16: Resposta do item $b$

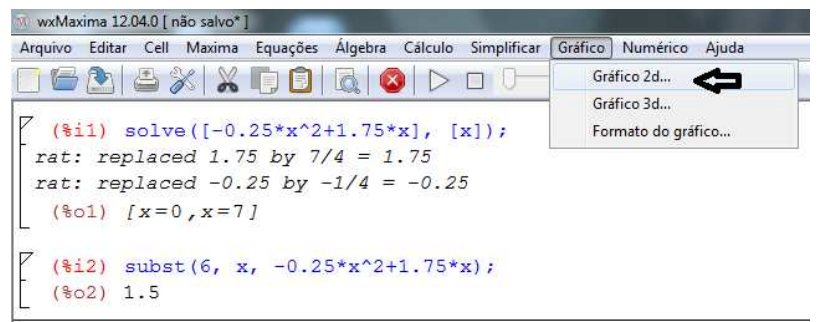

Figura 17: Menu Gráfico $\rightarrow 2 D$

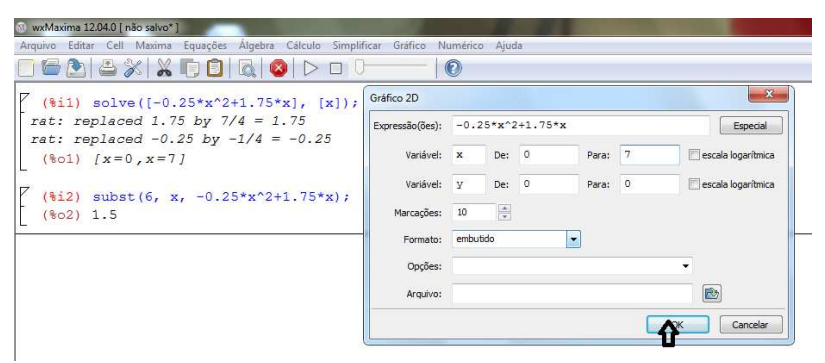

Figura 18: Lei da função digitada 


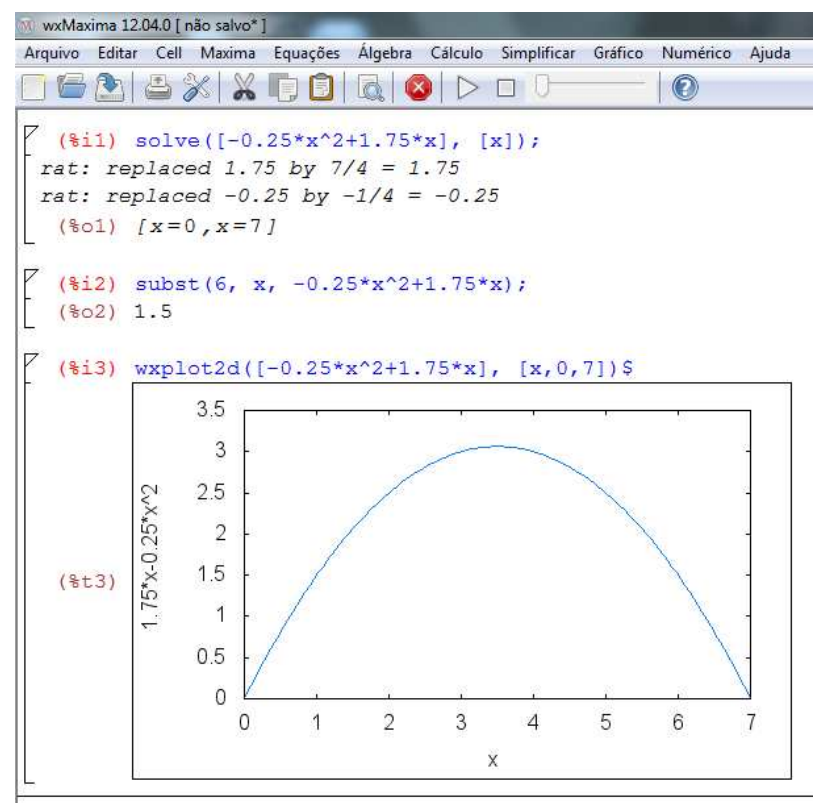

Figura 19: Resposta do item $c$

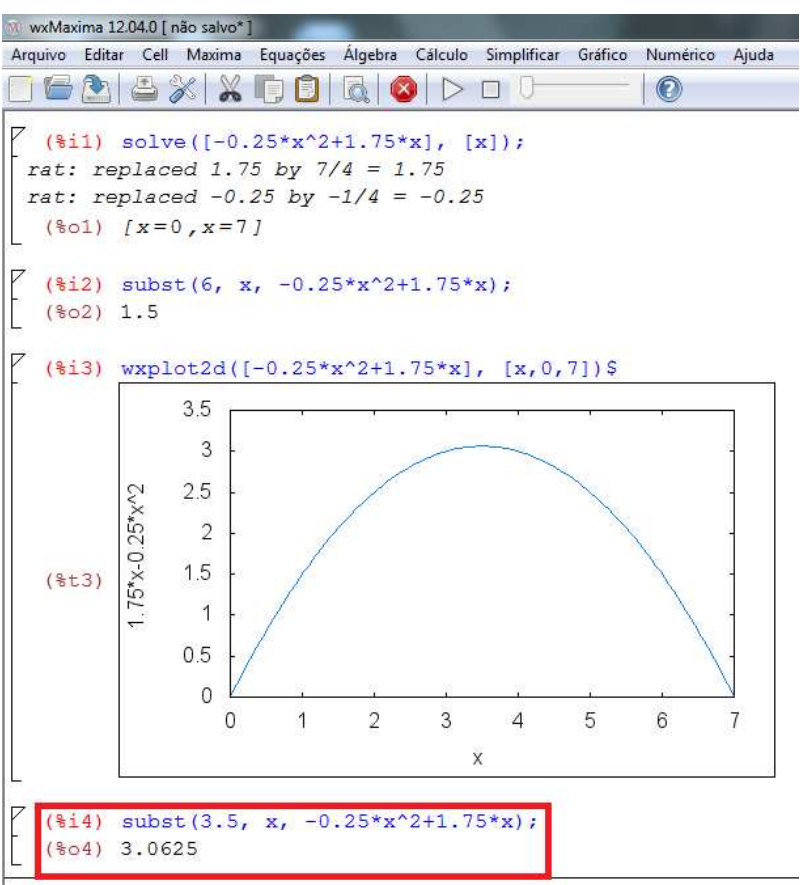

Figura 20: Altura máxima atingida pela bola

quando $x=3,5$ e seguir os passos do item $b$ ou ainda calcular $y=-\frac{\Delta}{4 a}$. Na Figura 20 consta que a altura máxima atingida pela bola é de 3,06m.
Pré-requisitos: Funções quadráticas - raízes, pontos de máximo e de mínimo, interpretação gráfica;

Material Necessário: Software wxMaxima instalado;

Tempo necessário: uma hora/aula.

Exercício 3. Considere um jogador de voleibol posicionado no fundo da quadra, na posição de saque. Sabendo que a trajetória da bola obedece a função $f(x)=$ $\frac{-x^{2}+12 x+13}{7}$, onde $x$ é o deslocamento horizontal da bola com relação ao jogador que a sacou e $f(x)$ é a sua altura.

Para resolver os itens, considere que:

- a altura da rede é de $2,42 m$ nos jogos oficiais masculinos e de 2,24m nos jogos femininos;

- a quadra tem $18 m$ de comprimento e a rede divide a quadra em duas partes iguais;

a) A bola ultrapassa a rede? Em caso afirmativo, ela cai dentro ou fora do lado adversário da quadra?

b) Considerando o jogador que dará o saque na origem dos eixos, a que distância dele a bola toca o chão?

c) Utilizando o software, determine qual é a altura máxima atingida pela bola?

d) Faça o gráfico de $f(x)$. O que acontece com o gráfico caso não se considere o denominador 7? Que diferenças gráficas podem ser notadas?

Resolução:

Dicas para o professor

• Peça aos alunos que considerem o jogador que vai sacar na origem dos eixos coordenados;

Lembre aos alunos que, para saber se a bola ultrapassa a rede, eles devem calcular $f(9)$ para concluir se a altura da bola será suficiente para passar para a quadra adversária;

Para resolver o problema devem ser seguidos passos semelhantes aos do exercício anterior, no qual também se utiliza o software wxMaxima.

a) A bola ultrapassa a rede? Em caso afirmativo, ela cai dentro ou fora do lado adversário da quadra?

Para concluir se a bola ultrapassa a rede, deve-se calcular $f(9)$, pois a rede está a $9 m$ do jogador que sacou a bola e este deve ser considerado na origem dos eixos. No wxMaxima, clique em simplificar $\rightarrow$ 


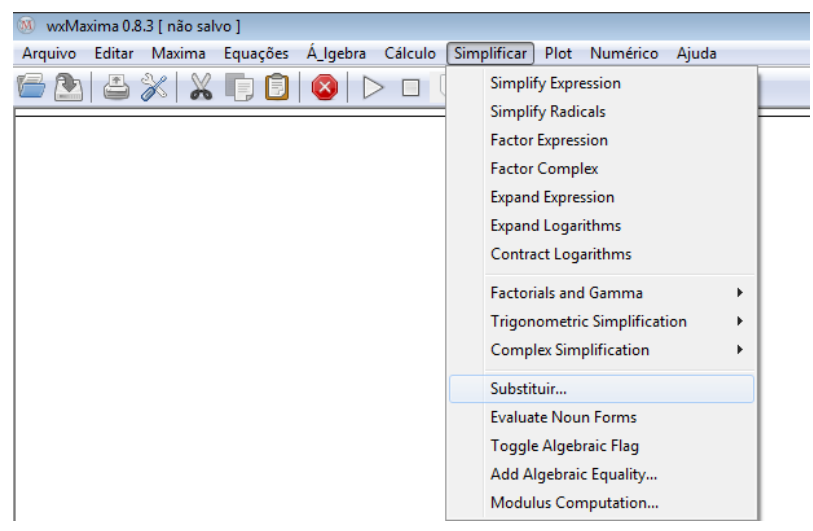

Figura 21: Menu Simplificar $\rightarrow$ substituir

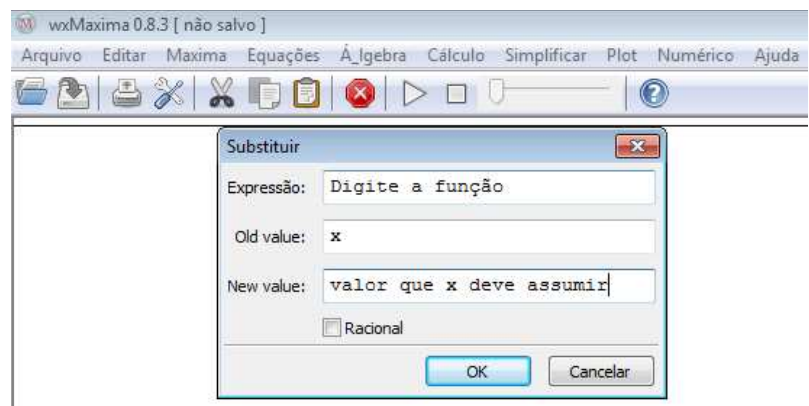

Figura 22: Digite a equação e o novo valor para $x$

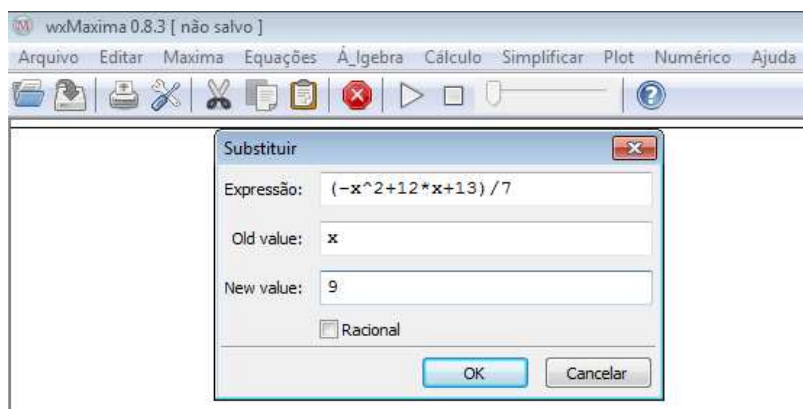

Figura 23: Equação e novo valor digitados

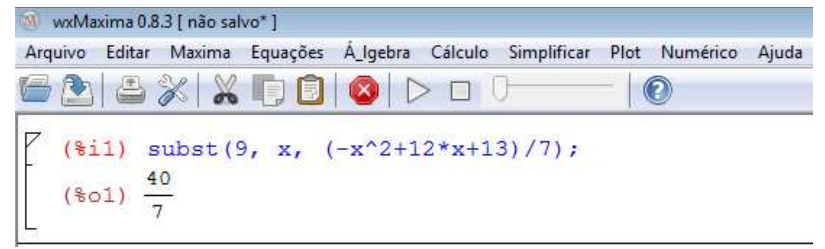

Figura 24: Valor de $f(9)$

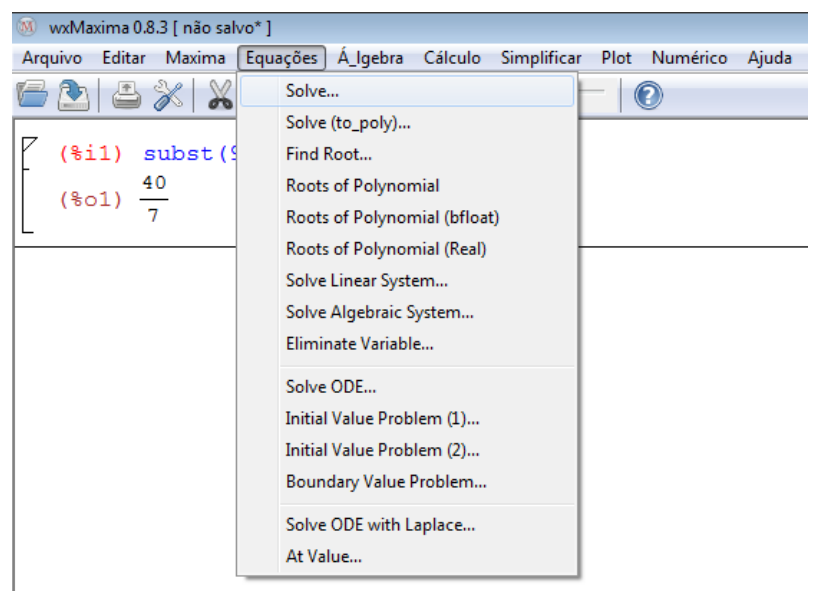

Figura 25: Menu equações $\rightarrow$ resolver

substituir, seguindo os passos das Figuras 21, 22 e 23.

Na Figura 24, tem-se a altura da bola na rede, que é $f(9)=\frac{40}{7} \approx 5,7143 \approx 5,71 \mathrm{~m}$. Como a bola está mais alta do que a rede, cuja altura varia entre $2,24 m$ e 2,42m, ela que consegue ultrapassá-la.

Agora o aluno precisa responder se a bola cai dentro ou fora do lado adversário da quadra. Para isso determine as raízes da equação, seguindo os passos das Figuras 25, 26 e 27.

Na Figura 28 estão as raízes da equação, $x=-1$ e $x=13$, segue que a bola cai a $13 m$ da origem, ou seja, na quadra adversária já que cada metade da

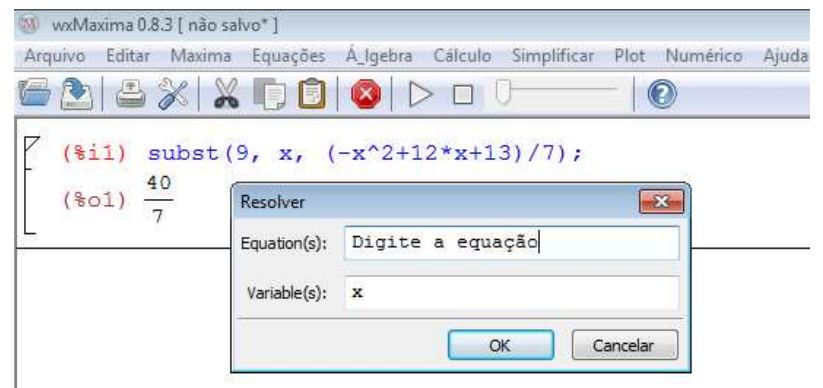

Figura 26: Digite a equação a ser resolvida 


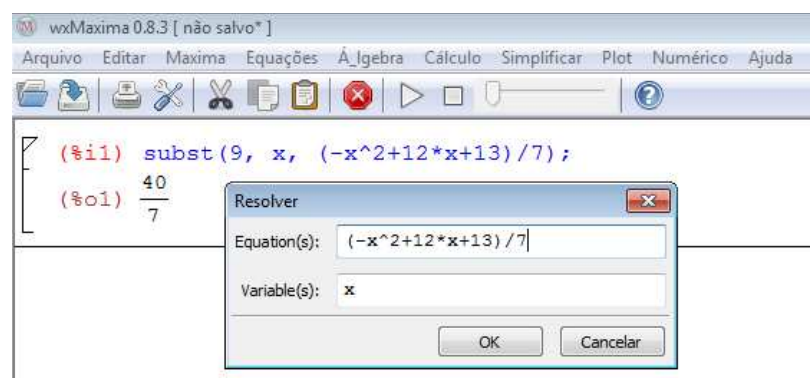

Figura 27: Equação digitada

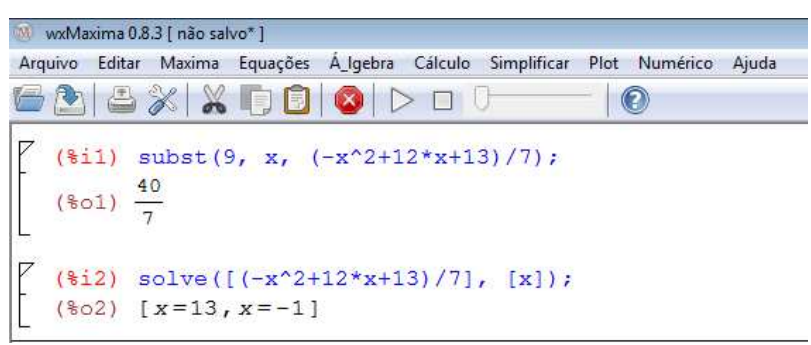

Figura 28: Raízes da equação

quadra tem $9 m$ de comprimento.

b) Considerando o jogador que dará o saque na origem dos eixos, a que distância dele a bola toca o chão?

Para determinar a que distância do jogador a bola toca o chão, basta considerar a raiz positiva da equação, observe na Figura 28 que a raiz positiva é $x=13$, isto é, a bola toca o chão à $13 m$ do jogador que à sacou.

c) Utilizando o software, determine qual é a altura máxima atingida pela bola?

Para determinar a altura máxima atingida pela bola, proceda como nas Figuras 21, 22 e 23. Lembrese que, pela simetria da parábola, o $x_{v}$ está equidistante de -1 e de 13, logo $x_{v}=6$. Na Figura 29 está o valor da altura máxima atingida pela bola, isto é, $f(6)=7 m$.

d) Faça o gráfico de $f(x)$. O que acontece com o gráfico caso não se considere o denominador 7? Que diferenças gráficas podem ser notadas?

Para resolver esse item deve-se clicar em plot $\rightarrow 2 D$, conforme Figuras 30, 31. Observe na Figura 32, o gráfico de $f(x)$.

Para fazer uma comparação gráfica, considere as funções $f(x)=\frac{-x^{2}+12 x+13}{7}$ e $g(x)=-x^{2}+$ $12 x+13$ e faça os dois gráficos em uma só janela, digitando as leis das funções conforme Figura 33.

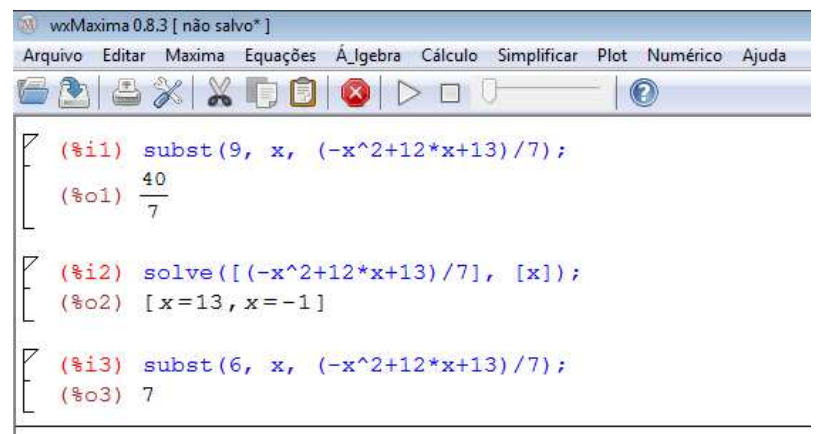

Figura 29: Valor da altura máxima atingida pela bola

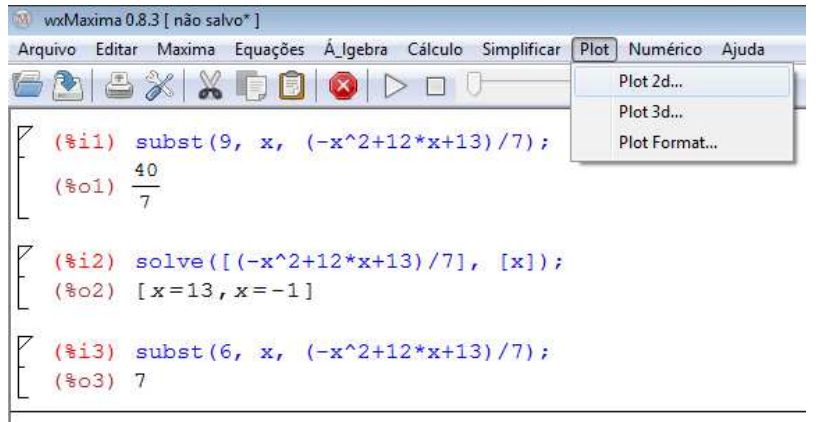

Figura 30: Menu plot $\rightarrow 2 \mathrm{D}$

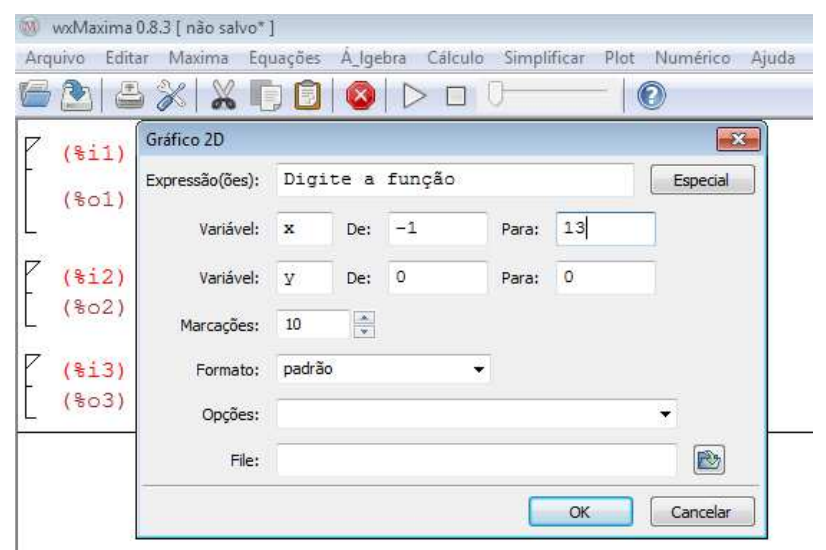

Figura 31: Digite a lei da função 


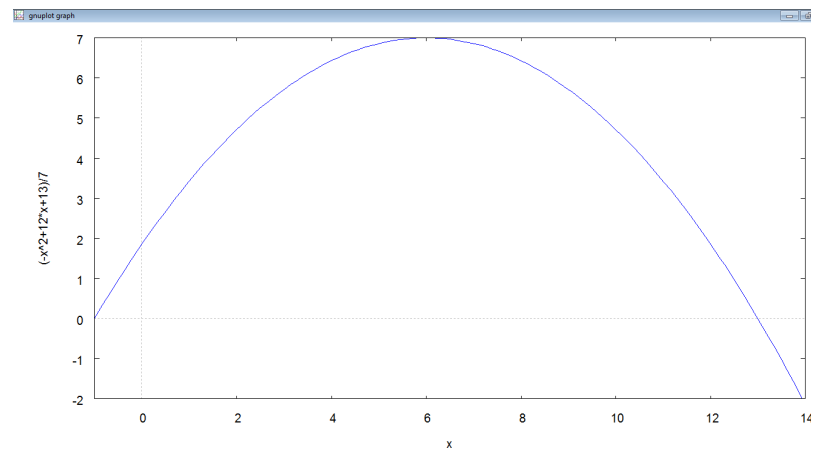

Figura 32: Gráfico de $f(x)$

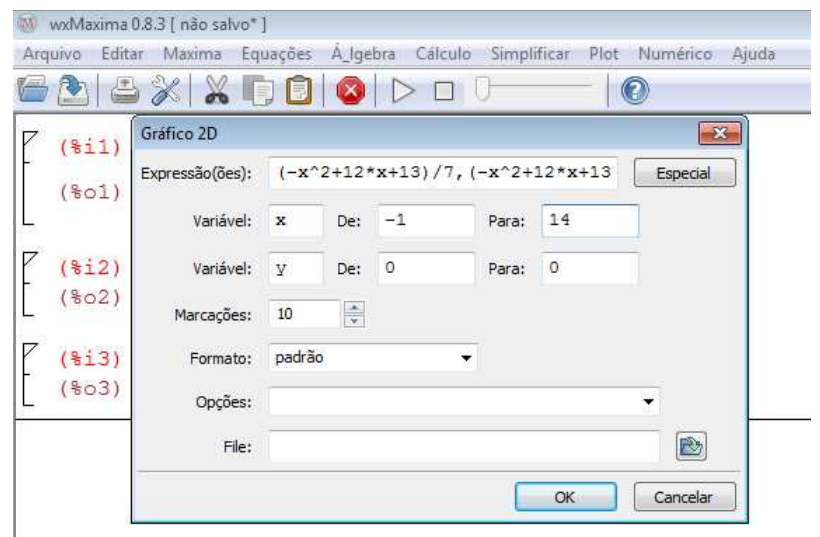

Figura 33: Leis das funções digitadas e intervalo fixado

Na Figura 34, tem-se os gráficos das funções $f(x)$ e $g(x)$, observe que mesmo as funções tendo as mesmas raízes, existe diferença gráfica, pois para todo $x \in D(f), g(x)=7 f(x)$, daí a importância de não eliminar o denominador de $f(x)$.

\subsection{Problema de análise gráfica}

A terceira atividade envolve construção e análise gráfica.

Atividade 3. Carro

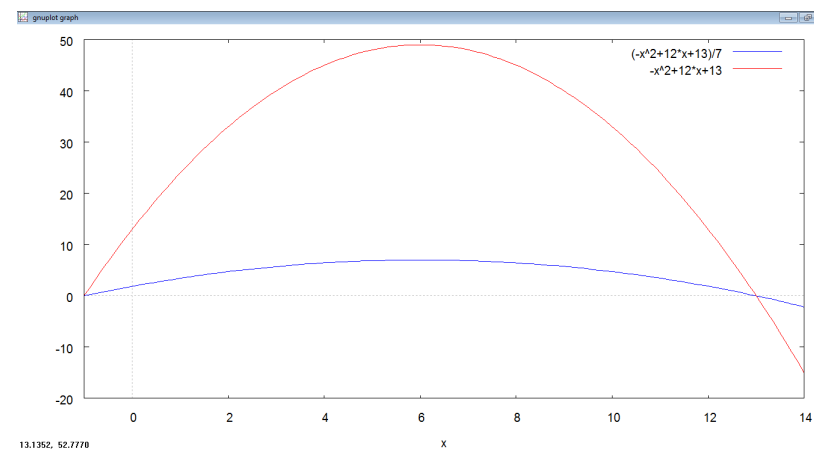

Figura 34: Gráficos de $f(x)$ e $g(x)$

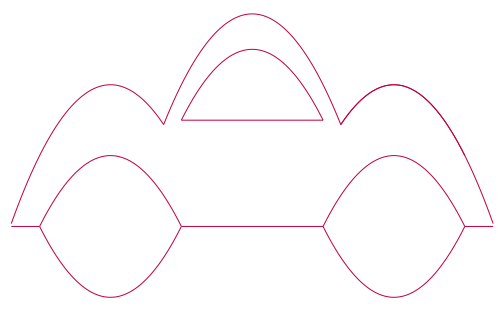

Figura 35: Carrinho

Pré-requisitos: funções quadráticas, construção gráfica e translações verticais e horizontais.

Material necessário: equipamento que tenha instalado o software Winplot ou similar.

Tempo necessário: Uma hora aula.

Exercício 4. Reproduza o desenho da Figura 35 utilizando o software Winplot.

Resolução:

Dicas para o professor

Relembre com seus alunos como fazer as translações horizontais e verticais das parábolas;

Incentive-os a buscar soluções diferentes da apresentada, pois pode-se chegar a um desenho muito semelhante utilizando outras funções quadráticas;

Lembre-os de que, para ter uma reta paralela ao eixo $O X$, deve-se fazer $y=$ $c$, onde $c$ é uma constante qualquer;

Explique aos alunos que não é necessário fazer um desenho igual ao dado, mas semelhante, pois o objetivo é exercitar como transladar funções.

A solução apresentada é uma possibilidade, mas outras soluções podem ser elaboradas pelo professor e pelos alunos.

Você pode começar fazendo a parte de cima do carrinho. Para isso, construa o gráfico da função $y=-x^{2}+3$ restrita ao intervalo $[-1,25,1,25]$, para fazer o gráfico limitado, através do comando Equação $\rightarrow$ Explícita. Digite a função e clique em Travar Intervalo. Veja na Figura 36 o resultado obtido.

Para construir os para-lamas deve-se deslocar horizontal e verticalmente a parábola, $y=-(x-2)^{2}+2$ limitada no intervalo $[1,25,3,41]$. Para desenhar o outro para-lama, faça o gráfico da função $y=-(x+2)^{2}+2$ com $x \in[-3,41,-1,25]$. Veja na Figura 37 a construção de um para-lama. 


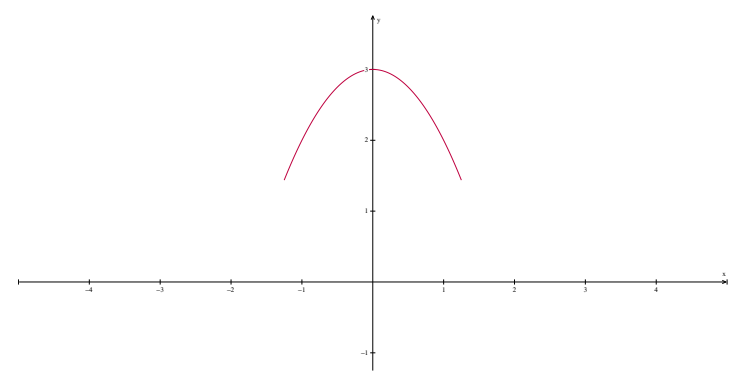

Figura 36: Gráfico que representa a parte superior do carrinho

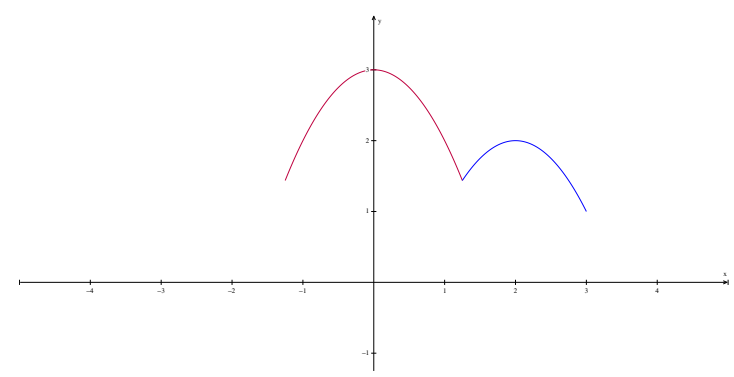

Figura 37: Gráfico que representa a parte superior e um dos para-lamas

Para esboçar a roda traseira (ou dianteira), utilize as funções $y=(x-2)^{2}-1$ e $y=-(x-2)^{2}+1$, ambas limitadas ao intervalo $[1,3]$, conforme a Figura 38. Para construir a outra roda, use as funções $y=(x-2)^{2}-1$ e $y=-(x-2)^{2}+1$, limitadas no intervalo $[-3,-1]$. Observe a Figura 39. Agora faltam apenas a janela e os acabamentos entre as rodas.

Para a construção da janela, use a função $y=-x^{2}+$ 2,5 e $y=1,5 \operatorname{com} x$ variando em $[-1,1]$. Nas Figuras 40 e 41 encontra-se o carrinho quase concluído.

$\mathrm{O}$ acabamento entre rodas do carrinho é feito pela função $y=0 \operatorname{com} x$ variando nos intervalos $[-3,41,-3],[-1,1]$ e $[3,3,41]$, os quais foram escolhidos por estarem próximos às raízes das funções que formam os para-lamas e rodas. As Figuras 42, 43 e 44 mostram a conclusão do desenho do carrinho.

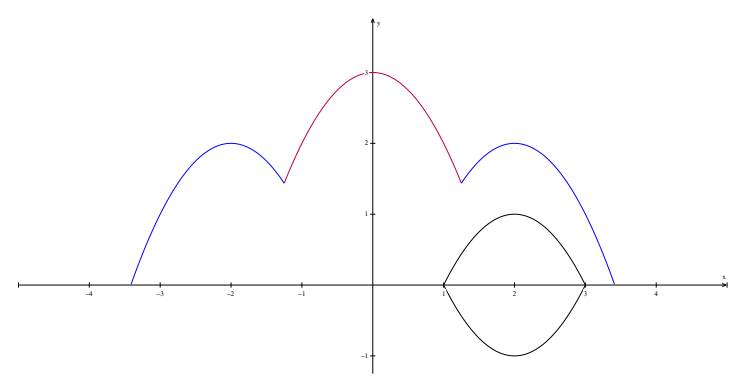

Figura 38: Construção da roda dianteira ou traseira

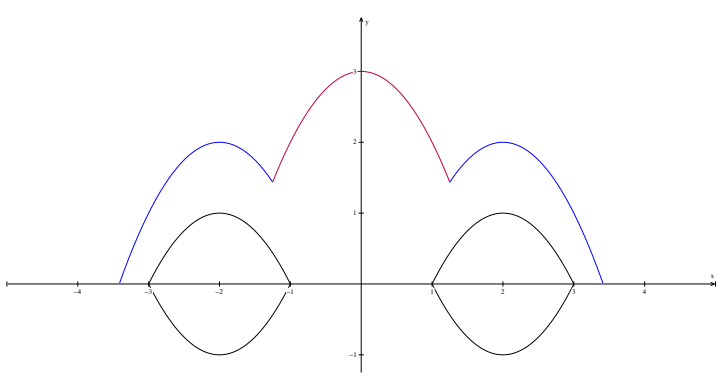

Figura 39: Carrinho com as duas rodas

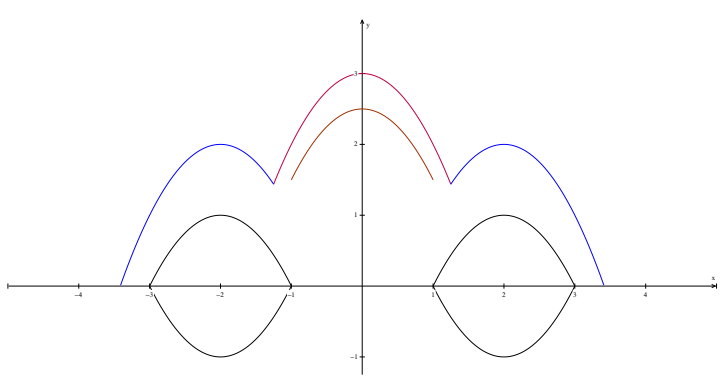

Figura 40: Construção da janela

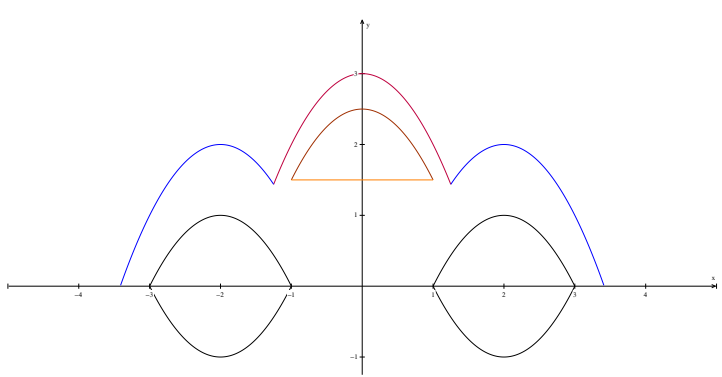

Figura 41: Janela concluída

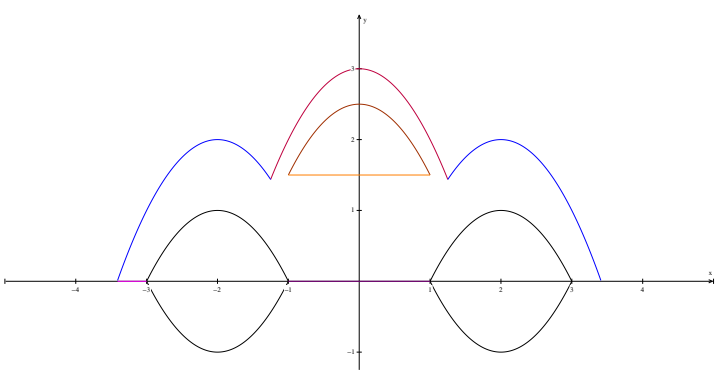

Figura 42: $y=0$ com $x$ pertencente ao intervalo $[-3,41,-3]$ 


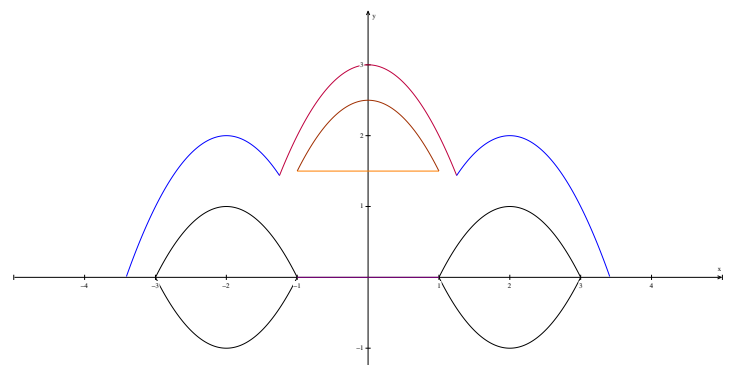

Figura 43: $y=0 \operatorname{com} x$ pertencente ao intervalo $[-1,1]$

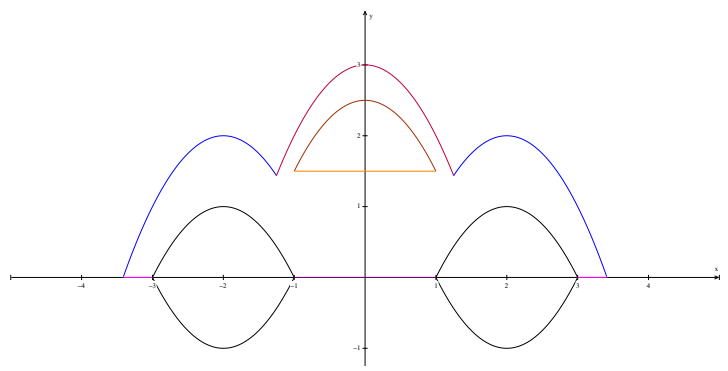

Figura 44: Desenho concluído

Para deixar todo o carrinho na mesma cor, acesse a janela inventário, escolha uma a uma as funções, clique em editar e após em cor, para só então, definir a cor desejada. Veja a Figura 45.

\section{Conclusões}

O ensino de matemática enfrenta, nos últimos tempos, grandes problemas que implicam em altos índices de reprovação, de evasão escolar e até mesmo a falta de interesse dos alunos. Também existe a falta de contextualização da matéria, que acaba por torná-la cada vez mais incompreensível aos olhos dos alunos, pois "embora pura e abstrata em sua nascente, a matemática sempre atendeu a objetivos essenciais e práticos"(Almeida (1987)).

Tentando resgatar esse caráter prático da matemática,

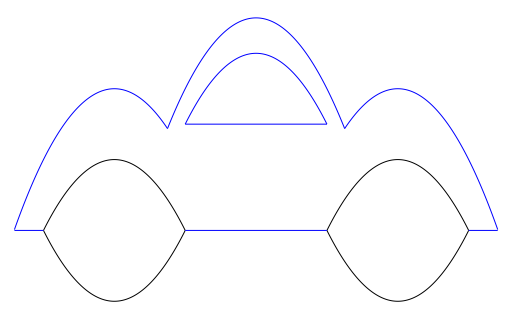

Figura 45: Desenho do carro em cor única através desse trabalho, disponibilizaram-se exercícios contextualizados e de produção gráfica aos professores para serem resolvidos utilizando softwares matemáticos livres, trazendo assim mais tecnologia e motivação para a sala de aula. Procurou-se dar ao estudo de funções quadráticas um enfoque semelhante ao que foi dado na disciplina de Funções durante o curso do Profmat, privilegiando o raciocínio do aluno e não a utilização direta de fórmulas nas resoluções.

No decorrer deste trabalho foi realizada uma pesquisa bibliográfica em livros didáticos de Ensino Fundamental e Médio. Fez-se também uma pesquisa sobre a utilização de softwares no estudo de funções e pôde-se constatar que, na maior parte das vezes, os softwares são utilizados para estudar o gráfico das funções quadráticas ou funções lineares contextualizadas. O grande diferencial deste trabalho reside na tentativa de revisar conceitos importantes de funções quadráticas utilizando os softwares winplot e wxMaxima.

Foram apresentados três atividades envolvendo esportes, duas tratam do tema futebol e uma sobre o voleibol e uma atividade envolvendo construção gráfica. Em todos os exercícios são disponibilizados os pré-requisitos, o material e o tempo necessários para a resolução dos mesmos em sala de aula.

Ao longo do trabalho, observa-se que a utilização de tecnologias no estudo de funções quadráticas pode ser um excelente recurso para auxiliar os professores nas suas aulas, tornando-as mais atrativas e significativas aos olhos dos alunos que se sentirão mais entusiasmados com o estudo dessa disciplina. Além disso, através da resolução dos exercícios, é possível perceber que os softwares utilizados não resolvem os problemas sozinhos. A solução completa dos problemas ocorre através da interação professor-aluno- software, fortalecendo, assim, as relações entre eles.

\section{Referências}

Alexandre, E., 2012. O estudo de funções quadráticas utilizando o Excel.

URL http://ntmsaojose.blogsplot.com.br

Almeida, F. J., 1987. Educação e Informática: Os computadores na escola. Cortez, São Paulo, SP, Brasil.

Almeida, F. J., 1998. As aparências enganam. MEC, Brasília, Brasil, Ch. 12, pp. 73-85.

Ambrósio, U. D., 1986. Da reflexão à ação. Editora da Universidade Estadual de Campinas, Campinas, Brasil.

Ávila, G., 2003. Cálculo das funções de uma variável. LTC, Rio de Janeiro, RJ, Brasil. 
Ávila, G., 2004. Funções e gráficos num problema de freagem. Brasília, DF, Brasil.

URL http://portal.mec.gov.br

Brasil, 2000a. PCN+ Parâmetros Curriculares Nacionais + - Ensino Médio. Ministério da Educação.

URL http://portal.mec.gov.br

Brasil, 2000b. PCN Parâmetros Curriculares Nacionais Ensino Médio. Ministério da Educação.

URL http://portal.mec.gov.br

Conceição, M. R. F., 2013. Transformações no plano. Mestrado, Universidade Federal do Rio Grande, Rio Grande, Brasil.

Fonseca, V. G., 2011. O uso de tecnologias no ensino médio. Mestrado, Universidade Federal do Rio de Janeiro, Rio de Janeiro, Brasil.

Gonzatto, M., 2012. Por que 89 por cento dos estudantes chegam ao final do ensino médio sem aprender o esperado em matemática? Jornal Zero Hora.

Junior, R. C. V. A., 2013. Desenvolvimento de conceitos e resolução de atividades de função quadrática com o uso do software geogebra. Mestrado, Universidade Federal de Mato Grosso do Sul, Campo Grande, Brasil.

Magarinus, R., 2013. Uma proposta para o ensino de funções através da utilização de objetos de aprendizagem. Mestrado, Universidade Federal de Santa Maria, Santa Maria, Brasil.

Maia, D., 2007. Função quadrática. Mestrado, PUC São Paulo, São Paulo, Brasil.

Neves, C. D. S., 2008. Uso de tecnologias no estudo de funções reais de uma variável real. Monografia, Universidade Jean Piaget, Cabo Verde.

Ribeiro, D. M. A. A., 2013. Uma abordagem didática para a função quadrática. Mestrado, Universidade Federal do Norte Fluminense - Darcy Ribeiro, Rio de Janeiro, Brasil.

Sancho, J. M., 1998. Para uma tecnologia educacional. Artmed, Porto Alegre, RS, Brasil.

Santos, D. S., 2013. O desenvolvimento de um aplicativo para o estudo de funções quadráticas. Mestrado, Universidade Federal do Piauí, Teresina, Brasil.

Shitsuka, R., Pereira, A. G., Shitsuka, C. D. W. M., de Junior Araujo, C. F., Shitsuka, D. M., de Paiva, E. J., Rosetti, H. J., Silveira, I. F., Schimigue, J., Calejon, L. M. C., de Castro Lugli, L., Shitsuka, R. I. C. M., 2012. Estudo e aplicações em ensino aprendizagem de matemática. Ciência Moderna, Rio de Janeiro, RJ, Brasil.
Toledo, M., 1997. Didática de matemática. FTD, São Paulo, Brasil.

Valente, J. A., 1998. Análise dos diferentes tipos de software usados na educação. MEC, Brasília, Brasil, Ch. 14, pp. 91-111. 